\title{
Mexico City in Space and Time
}

\author{
Kevin Chrisman, York University
}

Ageeth Sluis, Deco Body, Deco City: Female Spectacle and Modernity in Mexico City, 19001939 (Lincoln: University of Nebraska Press, 2015). 396 pp. \$35.00 Paperback.

Mauricio Tenorio-Trillo, I Speak of the City: Mexico City at the Turn of the Twentieth
Century (Chicago: University of Chicago press, 2012). 528 pp. $\$ 27.00$ Paperback.

Claudia Agostoni, Monuments of Progress: Modernization and Public Health in Mexico City, 1876-1910 (University of Calgary Press, 2003). 228 pp. \$45.00 Hardcover.

Historians have used a variety of theories and methods to analyze the built environment and urban spaces of Mexico City from its colonial period to the present. The sprawling metropolis contains the pulse of Mexican society. It is the center for a wide range of historical inquiries that describe its cultural and economic significance. During the postrevolutionary period, Mexico City experienced a dramatic increase in population growth. Spurred by a large influx of displaced migrants escaping the bloodshed of the Revolution, the capital swelled with people attempting to find shelter and opportunity. This was followed by a period of rapid industrialization that created job opportunities that contributed to a huge rise in urban growth. Mexico City is particularly momentous in today's industrialized world. One might imagine the historiography of Mexico City to be completely saturated with theoretical spatial histories that describe the built environment. And yet, a definitive spatial history of Mexico City remains noticeably absent from the historiography. There remains to be written a history of the capital that explores space with the same critical, theoretical, and intellectual vigor as other major cities, like Brasilia or London to name just a few examples. ${ }^{1}$ It is the purpose of this essay to compare some of the ways historians of Mexico City have applied space methodologically in their analyses of the built environments and inhabitants of Mexico City. It will also explore where conceptions of space and place connect dialogically with other spatial theories.

This essay is influenced by what Michel Foucault, Nikolas Rose, and Michael Dean refer to as "governmentality." It is through this process that cultural producers, government officials, and the ruling elite exercise and justify their power through a variety of large-scale social projects that shape the built environment. In cities, the elite justification for controlling public mentalities and space are the essential features for implementing social control. The command over space, time, and money forms what David Harvey describes as the "substantial nexus of social 
power" that links important networks to the hegemonic power within capitalist societies. $^{2}$

Historians of Mexico City who analyze state plans for urban development often identify elite conceptions of progress and modernization as the critical rationale behind large-scale alterations to the physical landscape. Borrowing from positivist currents and sciences popularized in Europe and the United States, nineteenth century elites during the dictatorship of Porfirio Díaz (1876-1910), seized on a modernizing gaze of Mexico City and used public work projects; such as the construction of a drainage canal, and the construction of state monuments in public spaces, to symbolize progress and order. In her work Monuments of Progress (2003), Claudia Agostoni focuses on the Porfirian government's efforts to control the urban environment, and how elites altered the social habits of the urban poor. Her research focuses on the discourses shaped by public health officials, engineers, and the state who envisioned an ordered and deodorized environment to overcome Mexico City's systemic problems with flooding, and the poor sanitary practices of urban dwellers. ${ }^{3}$ Agostoni argues that elite motivations to "alter the physiognomy and functioning of the city became a crucial factor in the symbolic legitimization of the Porfirian state at a time when the capital was reasserting its supremacy over the entire valley of Mexico and the rest of the nation." 4

Agostoni locates a critical linkage between the foreign and domestic capital expenditure funneled into public work projects, and the increasing regulation of social functionality as the Porfirian government attempted to centralize its power. Though the author formulates her argument well to explain how the city was shaped in part by the pragmatic efforts of elites and the scientific approaches formulated by hygienists and specialists, David Harvey might argue that Agostoni did not adequately account for the relationship between modernist transformations of space and the element of time within the nexus of social power. Harvey theorizes that capitalist societies yearn for increased social efficiency in order to reduce the "time horizons" spent on decision making. Thus, states view modernizing efforts as signs of social efficiency. But how might a modernist project like Mexico City's sewage canal reshape the production of time? Though Agostoni does not explicitly focus on the social implications of the sewage canal as related to its alteration of time, we may read through her findings to connect her analysis with Harvey's theory of the social nexus of power.

By alleviating the critical issue with social governance, the drainage canal would solve Mexico City's chronic flood problems. Elites in Mexico City viewed the chronic flooding as unhealthy and socially inefficient, but their main concern was primarily economic in nature. The floods caused delays in worker productivity and inhibited the ability for citizens to effectively perform their social functions and duties within the larger system of governance. The construction of drainage and sewage canals inevitably transformed time on an individual level. According to Agostoni, the large-scale public work projects "gradually penetrated homes and 
workplaces" and transformed the "bodily pleasures" and daily lives of Mexico City's residents. She argues the "vast socio-sanitary domain" forever altered the social landscapes above ground and below. ${ }^{5}$

Both Agostoni and Harvey primarily focus on the modification of urban landscapes from a top-down perspective. Yet, both offer specific ideas that consider different social ramifications. Harvey at one point describes the imaginative "worker," while Agostoni describes the transformative capital as benefiting the minority opulent. It is unclear from reading Agostoni how the general population utilized the state's social engineering projects for their own advantage. The sources used in her study prevent a reading of the public's reaction, or an understanding of how Mexico City's residents adapted to these modernizing efforts. Elites may have used large-scale public work projects in response to what they perceived as detrimental health conditions, but residents of Mexico City also interacted in these spaces and created their own environment free from state authority.

Yet, it remains unclear from reading Agostoni if elite reconfigurations of social spaces through their modernizing projects were universally accepted and practiced. For example, new social regulations and ordinances banned the contamination of canals and forbid citizens from collecting water from drinking fountains located in the plazas. However, it cannot be determined from Agostoni's study if residents of Mexico City complied with these regulations, or resisted the state's attempts to interfere with their way of life. A sociocultural approach to Mexico City's largescale public health projects may elucidate how Mexicans understood their own subjectivity within the modernizing efforts of the state. Whether state efforts to alter the social nexus of power significantly changed the ways in which Mexicans carried out their daily lives remains a looming question.

Agostoni's Monuments of Progress shares distinct commonalities with two notable theoretical approaches: James Scott's political examination of high modernism, and Nikolas Rose's critical analysis of professionalization and experts in state conduct. ${ }^{6}$ Scott would likely argue that Porfirian-era public work projects fit the criteria of modernism that he describes in his study, Seeing like a State (1998). However, it is less clear whether the utopian visions of hygienists and engineers would be deemed "failures" according to Scott's study, for it is generally accepted that the eradication of filth and disease from city streets, and the promotion of public health and the general wellbeing of human beings are sound fundamental achievements. Thus, one can only compare Agostoni with Scott to a certain extent before their associations deteriorate. It appears, however, that the Porfirato shared all the required ingredients necessary for what Scott would have considered the making of a utopian engineering disaster. ${ }^{7}$ The Díaz dictatorship was a highly authoritarian government that attempted to centralize its power throughout the national boundaries through the use of coercive practices. The government reinforced its own popularity through symbolic performativity, such as state-sanctioned festivals and monument ceremonies, which offered public stages to project its legitimacy. 
The Porfirian government also demonstrated its ability to control nature, and reordered the physical landscape through the construction of large-scale social engineering projects. Railroads, paved avenues, sanitation works, and the creation of large public spaces with state monuments bridged the colonial period into a modernizing Mexico. These state projects helped forge a new history that made sense of a tumultuous past. These state projects also helped citizens comprehend large social changes. These descriptions of the Porfiriato certainly fit the schema of modernism argued by Scott.

More specifically, a critical linkage is formed when considering Scott's remarks about the "designers of the new order" and the development of a specialized class of experts "who wanted to use state power to bring about huge utopian changes in people's work habits, living patterns, moral conduct, and worldview.", One of the essential elements of Agostoni's research is her focus on the development of public health professionals and the engineers and hygienists who influenced political discourse with their production of knowledge and visions for Mexico City's growth and modernity. As Agostoni observes, this specialized class became the "physicians" of Mexico City, and the "agents of civilization" who utilized state power to promote their own interests in the nation.

The rise of a specialized technocratic authority in Mexico City speaks dialogically to the theoretical observations explored by Nikolas Rose in his article "Expertise and the Government Conduct" (1994). As Rose observes, politics have seen a dramatic proliferation of a professionalized class of experts. These experts have acquired special authorities and social power through their possession of technical knowledge, and their ability to influence government by providing solutions to national issues. These experts support the nation's 'governmentality', and refashion political culture by way of shaping discourse through their own designs and esoteric language. According to Agostoni, hygienists created language barriers to separate themselves as the official experts in the modernizing program. ${ }^{9}$ The technical intelligentsia formed what Rose identified as "non-political modes of authority," whose multitude contributed to a diffusing of power into expanding realms of opportunities. In most ways, the city was viewed as a social laboratory for the specialized class to seek realms of visibility from the previously invisible social landscape. Agostoni describes state-sponsored public work projects as offering "evident, visible, and palpable" forms of power, extending the reach of government in society by using health policies. ${ }^{10}$ Experts offered recommendations that endorsed state plans to better society and contributed to a professionalized hierarchy claiming the technical sophistication for solving deeply rooted social problems. ${ }^{11}$ As Rose argues, experts exercise government while also becoming the agents of the state. ${ }^{12}$

In Mexico City, government experts worked to alleviate perceived social ills. As James Garza observes in The Imagined Underworld (2007), Porfirian elites imagined a criminal underworld existed within the lower class that was spreading disease, violence, and prostitution throughout Mexico City. ${ }^{13}$ The government formulated 
regulations and schemes to transform the city along elite conceptions of order and progress. In what Scott calls the "spatial unintelligibility" of the city, the state implored the technical advice of experts to alter society through massive public works projects. ${ }^{14}$ These experts found niches within the existing power structure to project their interests and support their domains of power while also drawing support to the Díaz regime. ${ }^{15}$ Porfirian elites depended on the cientificos, who were a specialized class of experts that competed for the state's legitimacy in the political landscape. Prior to the Mexican Revolution, citizens were largely exempt from participating in urban planning or shaping the national identity. ${ }^{16}$ Modernist projects like draining flood water from Mexico City could only become tangible through expert planning and state force. This depended on huge financial investments, strong political motivations, and the coercive power necessary to commence and design its practical application.

According to Rose, the proliferation of experts caused a dramatic political transformation to the existing hegemonic structures of government. This in turn allowed them to control certain sectors of society. Individuals acting within specific non-political domains; such as the public health sector, among other institutions; provided an advanced technical knowledge that helped support the state's effort to improve perceived problems that were impeding national progress. ${ }^{17}$ In other words, each social intervention further colonized the public and private spaces of the urban environment and molded a new sense of social normalcy for the modern citizen.

Government elites are primarily concerned with the spatial domains near the centers of power, constructing elegant palaces and monuments to impress visitors and project state power into public domains. ${ }^{18}$ Government construction projects in public spaces helped subject citizenry under state control. Monuments collapsed the past into identifiable political figures that projected state authority into public realms. Conversely, the state appears less concerned with seemingly isolated communities like the countryside, or areas unconducive to economic exploitation. It is here where government elites often depend on a process of political negotiation with regional power brokers who fulfill the state's function at a local level. Local elites simultaneously craft their own domain of power for themselves. This is a topic intrinsically connected to Rose's observations mentioned above, but outside the scope of this particular essay.

Doreen Massey has extended the theoretic discussion of spatial phenomena to include the meaning of place, mobility, and the exploration of subaltern subjectivity in the spatial process. ${ }^{19}$ Her article shares many commonalities with Harvey, and it appears they are dialogically linked through their ideas on time, space, and money. Both articles were published in the same year (1994) and work together to strengthen the recognition of capitalism's role with the command of space. However, Massey's approach of space in the city extends beyond the economic dimensions and capitalism by determining what shapes space and place at an individual level. ${ }^{20}$ According to Massey, to understand the city, we must place it within a wider 
geographical context. ${ }^{21}$ From Massey's reading, we gather that a critical component to spatial theory must include considerations for how race and gender transcend through time and space within geographical boundaries. Massey posits that we must connect different groups and individuals to the "power geometry of time-space compression" and understand the "differentiated mobility" between social actors and their environment. ${ }^{22}$ Unlike Harvey and Rose, Massey moves beyond simplistic binary categorizations of elite, (or expert) and non-elite actors by considering levels of power within "a highly complex social differentiation." Massey sees the direction of the historiography developing theories about the politics of mobility and access to space. She hints there needs to be a better view of spatial interaction at the street level, much in the way Jane Jacobs's ethnography The Death and Life of Great American Cities (1961) analyzed the everyday experience in the urban landscape.

Patrick Joyce's The Rule of Freedom (2003) in part, answers Massey's call to explore the politics of mobility. For example, in the same way highways provide a freedom to circulate around cities, they also reshape and collapse conceptions of place. ${ }^{23}$ Connecting with Harvey's articulations, one could also conclude that the command over forms of mobility also denies access to particular destinations. People have the mobility to explore space within certain sanctioned geographical boundaries. Future research might explore the environmental impact of the timespace compression, and the alteration of place and mobility for natural environments. Further analysis might help understand how transportation networks support power systems and function as the veins that connect populations to economic markets, and fasten people to the system of mass consumerism and material culture.

In Deco Body, Deco City (2015), Ageeth Sluis has brilliantly crafted an analysis of postrevolutionary Mexico that links changing conceptions of gender along with the changing urban landscape of Mexico City. In the wake of the Mexican Revolution, an influx of female migrants escaping rural violence in the countryside found shelter and opportunity in Mexico City. Their presence in the public space challenged traditional gender roles. Sluis describes the emergence of a new, modern femininity she calls "The Deco Body," which was influenced by transnational cosmopolitan ideas disseminated through entertainment and advertisements. As Sluis argues, this idealized female physique played out in the urban landscape and helped construct and visualize a "mestizo modernity." 24 The Mexican state responded to their perceived fears of "free women" in public spaces by imposing new forms of governmentality that created gendered regulations of the female body and their sexuality. ${ }^{25}$ Through large-scale public work projects, the Mexican state created spaces that contained the spectacle of female bodies in public places by building parks, monuments, theaters, and new colonias.

In her chapter "Promis-ciudad: Projecting Pornography and Mapping Modernity," Sluis examines the promiscuous magazine Vea (Look), which contained sexual narratives and nude photos of female bodies superimposed over recognizable public spaces in Mexico City. The magazine was later banned by state regulators. 
Sluis uses the magazine as a lens to focus on the larger narrative of female mobility, sexuality, and gender in Mexico City. ${ }^{26}$ She argues that pornography connected Mexico City to transnational conceptions of the modern woman. According to Sluis, the magazine conversed with elite conceptions of revolutionary nationalism and their gendered regulation of social spaces. ${ }^{27}$ What made Vea's magazine particularly radical to the revolutionary state was the type of pornography included in the pages. The images countered acceptable images of a traditional Mexican nudity associated with Indigenous females from the countryside, which was viewed as a pastoral and natural embodiment of true Mexican beauty. Instead, Vea projected an alternative form of female sexuality into the cityscape in stark contradiction to national currents which supported female domesticity. Using Massey's theory of place and gender, Sluis argues journalists used "gendered bodies as spatial vectors on which to plot nudity's movement from idyllic, pastoral camposcape (the traditional countryside) the erotic and dangerous space of pornotopia." 28 Vea's feminized urban landscapes and Deco-body images of the modern women equated to a counterhegemonic form of Mexican modernity.

Sluis' argument might be criticized for depending on her interpretations of images from $V e a$ rather than her interpretations of written documents. There remains little evidence outside of theoretical hypothesis to argue that Vea joined a public debate with revolutionary officials about gendered space. It is not known from this reading, for example, how Mexicans understood their relationship and experiences within the public "debate" concerning feminized spaces. As Scott aptly warns, "We must remain agnostic about the relation between formal spatial order and social experience," since state authority and elite regulations generally have little or relatively little relationship with citizens. ${ }^{29}$ However, Sluis might disagree with Scott on this juncture. As she argues, gendered regulations were part of the postrevolutionary policy to police public spaces and free them from threats of urban decay. Pornography was viewed as a form of vice, associated alongside Mexico's underclass and its perceived criminal underworld. That $V e a$ was eventually banned from publication suggests that the magazine stimulated certain fears within elite circles who may have viewed the projection of nude female bodies onto state monuments as a direct challenge to Mexico's national identity. Regardless, Sluis's work is highly provocative for its exploration of gender and visual culture as lenses to analyze Mexico City's urban environment. Sluis' utilization of Massey's concepts of gender and place provides an important methodological template for historians of Mexico City.

Mauricio Tenorio-Trillo's multidisciplinary synthesis I Speak of the City (2012) explores the urban spaces of Mexico City in very unique ways. The book contains a sweeping compilation of insightful essays on the urban experiences of Mexico City from 1880-1940. Using poetry, literature, architect, etiquette manuals, epidemiology, art, and memories of his own personal experiences, Tenorio-Trillo attempts to view Mexico City from its sidewalks and from the "global flows" com- 
ing from outside. His methodological approach to the city is most refreshing and breaks historical conformity. The book provides a template for historians to imagine and reimagine the "overlapping vistas" of Mexico City and its various spatial elements. ${ }^{30}$ Compared to others, this book is harder to dissect thematically in terms of space due to the shifting definitions in which it is described. In other words, Tenorio-Trillo discusses space but not explicitly to the degree as Massey, Agostoni, Harvey, or Scott.

Absent from the book index are references to space or theoretical models. Further, there are no historiographical sections or references to other Mexican urban scholars. The book reads arrogantly at times, as Tenorio-Trillo dismisses, for example, a scientific lens of Mexico City as "seemingly unsuitable to observe anything Mexican." ${ }^{31}$ Agostoni would most certainly disagree with this assumption. However, Tenorio-Trillo discusses space and spatial formulations in other unique ways. $\mathrm{He}$ explores Mexico City's "lived moments" from various perspectives and delves into the past to grasp the "chaotic mixtures" of knowledge and wonderings created and cast by buildings, monuments, streets, his own urban walks. ${ }^{32}$ Tenorio-Trillo tangentially connects to Massey by his imaginings of space and its effect on urban environments. In some ways, he wants to understand the connection between mobility and knowledge production at a local level, similarly to the way Sluis demonstrates visual culture projected femininity into the public domain. Theoretically, TenorioTrillo shares commonalities with Foucault's thoughts on the "discursive fact" in his History of Sexuality (reprinted, 1990). Foucault sought to locate forms of power and the permeation of discourses that shape individual modes of behavior in the lives of citizens. In a similar vein, Tenorio-Trillo explores Mexico City within a global context, and challenges the very meaning of "Mexico" as being captured within a set of historical assumptions that have been retold throughout the world as constituting an "authentic" version of being Mexican. One might further connect this imaginative view of Mexico City with Massey's ideas to place the city into a wider geographical context. ${ }^{33}$

Tenorio-Trillo also argues that Mexico has become Orientalized by cultural elites. Foreign writings, descriptions, and other cultural productions have imagined an exotic Mexico. ${ }^{34}$ In this vein, Tenorio-Trillo extends the spatial knowledge of Mexico City to include the perceptions of space as imagined by other cultures through an analysis of language. ${ }^{35}$ In what Tenorio-Trillo describes as the "Brown Atlantis," Mexico City was a laboratory that elites used to induce widespread social and cultural changes. This relates well with Harvey's thoughts on the command of space and political power. Viewed as a laboratory, Mexican Orientalists and intellectuals could shape social practice, and also define time and space, not just within the city limits, but within the world's exotic imagination of Mexico City. ${ }^{36}$ According to Harvey, cities are models of our imagination that are shaped by the "resistance they offer when we try and impose our own personal form on them." ${ }^{37}$ His sentiment underlines how urban spaces are contested landscapes where the state conjures 
its hegemony and the citizenry contest it. Mexican cultural elites borrowed from Spanish language ideological currents and manipulated these concepts to fit their own imagination, producing a distinctly Mexican social framework. This shares commonalties with Foucault's articulations about the "discursive fact" and the channeling of power into "perceivable forms," which propagates into other forms of knowledge and is eventually transmuted to the individual. ${ }^{38}$ In the way discourses shape knowledge production, they also create new circles of knowledge.

Tenorio-Trillo extends this dimension by thinking of knowledge beyond the power binary of knowledge producer and individual by thinking in universal terms. He argues that throughout Mexico City, knowledge is applied, acquired and marked by local social conditions. He states that "by the very fact of being on or about the city, it is also potentially a universal knowledge." ${ }^{39}$ Running with this ideological current, one could easily connect knowledge as a spatial domain of contestation intrinsically connected to the construction of the city. Social institutions disseminating forms of knowledge "command space" in the sense described by Harvey, and thus largely control the politics of society. Harvey states "spatial and temporal practices are never neutral in social affairs. They always express some kind of class or other social content." 40 Tenorio-Trillo describes the politicization of knowledge in Mexico City in his chapter on science and the city. He argues that Mexican elites used scientific knowledge as a powerful solution for social problems. The scientific institutions produced knowledge, which was then applied to Mexico City like it was a social body, creating a "circle of interaction" of discourse and its practical application. ${ }^{41}$

In terms of Tenorio-Trillo's methodological approach, he stresses that no meaningful historical analysis of a modern city may be absent from the personal experiences of the researcher. The visual interpretations of spatial phenomena are experienced personally, on the streets, which includes taking in the visual scenery and analyzing the various components that make up the social landscape. His expository essays explore space and place in ways other scholars might not ponder, like the social importance of dogs, beggars, and tezontle, a reddish volcanic stone. He conceptualizes the city by "zooming in" which allows him to consider local conditions with an approach commonly found in ethnography. Through this creative application of spatial imaginings, Tenorio-Trillo shifts his study radically away from other structural spatial histories of Mexico City, especially since he considers the importance of the city by also "zooming out." The inside and outside approach to his essay chapters allow us to think of Mexico City from multiple layers, exploring the "various cities" that construct Mexico City.

How did the former "City of Palaces" grow to become the overpopulated and uncontrollable megalopolis of today? Diane E. Davis' Urban Leviathan (1994) answers in part this question and explores the capital's political history, arguing that Mexico City's urban development and its consequences are based on the conflicts and alliances set between state and class actors over their efforts to effectively man- 
age the city. Davis expresses the circumstances behind the denial of political participation by local residents who were forced to use state institutions to express local concerns. She argues that "policy conflict, and administrative decisions about the growth, nature, and spatial or sectoral character of Mexico City have had direct repercussions on the national economy, on national corporatist political structures, and on the balance of power in national politics." 42

Davis' monograph draws striking comparisons to the spatial formulations posited by James C. Scott and the modernist city. She argues that Mexico City is an example of an urban development disaster designed by local and national political actors who sought an ideal, governable city through a specific reordering of urban space. As Scott argues, "As happens in many authoritarian modernizing schemes, the political tastes of the ruler occasionally trumped purely military and functional concerns. ${ }^{43}$ In the way elites and government officials organized and developed a very capitalist-oriented Mexico City, they ignored many important concerns for effective city planning, causing many of the serious problems experienced in Mexico City today. While Tenorio-Trillo attempted to globalize Mexico City by understanding the importance of language and the meaning of Mexico throughout the world, Davis concerns her book with local, regional, and national concerns. She connects Mexico City to national politics by tracing the economic forces inside and outside that contributed to the capital's urban development.

A noticeable friction appears when we try comparing Nikolas Rose's analysis of expertise and government conduct along with Davis' "realistic narrative" which explores the larger "developmental processes" of Mexico City including city infrastructure and transportation services. ${ }^{44}$ Davis combines sociological principles with theory and history to emphasize the importance of non-governing actors in contesting political hegemony. She borrows, for example, urban theorist and geographer Edward Soja's ideas on "spatiality," which considers the position of local determinants in social change and their unique place and time within history. ${ }^{45}$ Davis hones in on the centrality of local class actors and their spatiality within Mexico City's urban development. According to Davis, the middle class played a small but important role in shaping Mexico City's growth and development, and produced large-scale changes in Mexico City's politics. One might understand Davis as trying to expand our historical knowledge of the processes involved in negotiating power relations and the competing political discourses that shape the urban environment. Davis finds fault in the structuralist argument common among urbanists who read Mexico City as solely an elite formulation. According to Davis, one of the common misconceptions is to ignore human agency and view cities as an elite creation administered by a specialized class who function as state actors. She states that "if Mexico scholars focus only on national political teams or cadres of national bureaucrats, they merely reproduce the same misleading view of other urbanists: that an all-powerful national party apparatus overdetermines all policy and political developments in Mexico." 46 
For these reasons, Davis would likely find Rose's analysis on government conduct full of generalizations and lacking enough emphasis on the importance of local environments and their distinct geographical influences on the professionalized class. To Rose's credit, he mentions the existence of human agency within the spatial boundaries of power relations, but not with significant depth, and only to acknowledge their general existence as if individuals only reacted to the "lent vocabularies" of "certain knowledgeable persons." Rose does not, for example, focus on the agency of workers who operate the state's infrastructure. Nor does he focus on actors in local government that levy their power onto the national stage, something Davis brings forth in her analysis. To Davis, contemplating a holistic exploration into Mexico City's spatial development must account for "local-national" articulations that fit both social and state actors within a particular spatial context. ${ }^{47}$

In regards for the implementation of spatial theory into the works on Mexico City, Davis would likely find Tenorio-Trillo's book as lacking a clear theoretical component to define the larger issues pertaining to space, place, and time. Using spatial theories helps to contextualize the importance of Mexico City's unique historical experiences. Though theory is not absolutely necessary to understand spatial phenomena; as one gathers from reading Tenorio-Trillo, Davis recognizes it as important to "grasp unique as well as repeated events, and it does so in the narrative process." 48

Spatial theory allows us to not only imagine the city, but to discover the historical parallels that run through time and space. A new trend in the historiography of modern cities attempts to explore the links between space, cultural experiences, performativity, and the state. Analyzing the built environment helps demonstrate how state functionaries "capture agency" through spatial domains. And yet that same agency may become a form of resistance against power structures and their designs. ${ }^{49}$ There are countless examples that demonstrate the ways human interactions contest the state and reconfigure elite designs into their own ways. Just as states construct large symbolic monuments in public spaces to project their power and authority; as a not-so subtle reminder to citizens of their subjectivity within the social order; protestors often reclaim these spaces for their own, and use these locations as sites to contest hegemony and project their forms of power. Thus, space serves as an important symbolic and analytical tool for viewing many layers of culture and society. Viewed from above, space helps elucidate how states "see" and make the city more legible. Space may also explore the urban environment on the ground to explore how people create their own cities separate from elite conceptions. Through an examination of Mexico City, we can explore the varying degrees in which power structures are continually constructed, projected, shaped, and contested through space and time. 


\section{NOTES}

${ }^{1}$ See for example, James Holston, The Modernist City: An Anthropological Critique of Brasilia (Chicago: University of Chicago Press, 1989), James C. Scott's chapter on Brasilia, "The High-Modernist City: An Experiment and a Critique" in Seeing like a State: How Certain Schemes to Improve the Human Condition have Failed (New Haven: Yale University Press, 1998), 103-146, Mary Poovey, Making a Social Body: British Cultural Formation 1830-1864 (Chicago: University of Chicago Press, 1995, Katherine Kia Tehranian, Modernity, Space, and Power: The American City in Discourse and Practice (Cresskill: Hampton Press, 1995), Mark Overmeyer-Velazquez, Visions of an Emerald City: Modernity, Tradition, and the Formation of Porfirian Oaxaca, Mexico (Durham: Duke University Press, 2006).

2 David Harvey, The Condition of Postmodernity: An Enquiry into the Origins of Cultural Change (Cambridge: Blackwell, 1990), 226-227.

${ }^{3}$ Claudia Agostoni, Monuments of Progress: Modernization and Public Health in Mexico City, 1876-1910 (University of Calgary Press, 2003), xiv.

${ }^{4}$ Ibid., xiii.

${ }^{5}$ Agostoni, Monuments of Progress, 115.

${ }^{6}$ Nikolas Rose, "Expertise and the Government of Conduct," in Studies in Law, Politics, and Society, Susan S. Sibley and Austin Sarat, eds. Vol 14 (Greenwich: JAI Press, 1994), pg. 359-394.

${ }^{7}$ Scott, Seeing like a State, 4.

${ }^{8}$ Scott, Seeing like a State, 5.

9 Agostoni, Monuments of Progress, 27.

${ }^{10}$ See for example, Claudio-Lomnitz, Exits from the Labyrinth: Cultural and Ideology in the Mexican National Space (Berkeley: University of California Press, 1992).

11 Rose, "Expertise and the Government of Conduct," 374.

12 Rose, "Expertise and the Government of Conduct," 366.

${ }^{13}$ James A. Garza, The Imagined Underworld: Sex, Crime, and Vice in Porfirian Mexico (Lincoln: University of Nebraska Press, 2007).

14 Scott, Seeing like a State, 55.

${ }^{15}$ Rose, "Expertise and the Government of Conduct," 360.

${ }^{16}$ William E. French, "Imagining and the Cultural History of Nineteenth-Century Mexico," The Hispanic American Historical Review, Vol. 79, No. 2, Special Edition: Mexico’s New Cultural History: Una Lucha Libre (May, 1999), 253. 
17 Agostoni, Monuments of Progress, 116.

${ }^{18}$ Scott, Seeing like a State, 62.

19 Doreen Massey, "A Global Sense of Place," in Space, Place, and Gender (Minneapolis: University of Minnesota Press, 1994).

20 Ibid., 2.

21 Ibid., 8.

22 Ibid., 3.

${ }^{23}$ Patrick Joyce, The Rule of Freedom: Liberalism and the Modern City (London:

Verso, 2003), 242.

${ }^{24}$ Ageeth Sluis, Deco Body, Deco City: Female Spectacle and Modernity in Mexico City, 1900-1939 (Lincoln: University of Nebraska Press, 2015), 18.

${ }^{25}$ Ibid., 2.

${ }^{26}$ Ibid., 138.

27 Ageeth Sluis, "Projecting Pornography and Mapping Modernity in Mexico City," Journal of Urban History 38(3), (2012), pg. 467-468.

28 Ibid., 475.

${ }^{29}$ Scott, Seeing Like a State, 58.

${ }^{30}$ Mauricio Tenorio-Trillo, I Speak of the City: Mexico City at the Turn of the Twentieth Century (Chicago: University of Chicago press, 2012).

${ }^{31}$ Ibid., xxiii.

32 Ibid., xiv.

33 Massey, "A Global Sense of Place," 8.

34 Tenorio-Trillo, I Speak of the City, 418.

${ }^{35}$ Michel Foucault, The History of Sexuality, trans. Robert Hurley (New York: Vintage Books, 1990), 11.

${ }^{36}$ Harvey, The Condition of Postmodernity, 234-235.

37 Ibid., 5.

${ }^{38}$ Foucault, The History of Sexuality, 11.

39 Tenorio-Trillo, I Speak of the City, 286.

${ }^{40}$ Harvey, The Condition of Postmodernity, 234.

41 Tenorio-Trilllo, I speak of the City, 287.

Diane E. Davis, Urban Leviathan: Mexico City in the Twentieth Century (Philadelphia: 
Temple University Press, 1994), 4.

Scott, Seeing like a State, 62.

Davis, Urban Leviathan, 14.

Ibid.,12.

Ibid.,12.

${ }^{47}$ Ibid., 13.

${ }^{48}$ Ibid., 14.

${ }^{49}$ Pryce, The Rule of Freedom, 184. 